\title{
Correction of relative risk in neonatal sepsis
}

\author{
Carlos Martín Corral-Chávez
}

Universidad Autónoma de Durango, Campus Los Mochis, School of Medicine, Sinaloa, Mexico

Respectable editor.

I read with interest the article "Prolonged exposure to antibiotics and the risk of late-onset sepsis (LOS) in neonates of 1000-1500 g: a cohort study", by doctor Briones Lara.," published at Gaceta Médica de México.

The authors calculated the relative risk $(\mathrm{RR})$ in two groups of neonates: exposed (receiving antibiotics for $>5$ days) and non-exposed ( $<5$ days), with the probability for developing late-onset sepsis and necrotizing enterocolitis in premature neonates with 1000 to $<1500 \mathrm{~g}$ body weight. They reported an incidence of late-onset sepsis of $65.3 \%$ (32/49) in exposed and $8.1 \%(4 / 49)$ in non-exposed neonates, and $24.5 \%$ (12/49) and $4.0 \%$ (2/49), respectively, for necrotizing enterocolitis.

The reported RR calculated for developing late-onset sepsis was $21.1(95 \% \mathrm{Cl}=6.5-68.9)$, a figure that actually corresponds to the odds ratio $(\mathrm{OR})$; the corrected RR for late-onset sepsis must be 8.6 (95\% $\mathrm{Cl}=3.05-20.9$ ). Similarly, the RR for developing necrotizing enterocolitis that was indicated was 7.6 (95\% $\mathrm{Cl}=1.6-36.1)$, which should be $6.0(95 \% \mathrm{Cl}=1.4-$ 25.4). The RR correction was performed using Epi-info version 7.2 for Windows. ${ }^{2}$

In cohort studies, RR and OR can be estimated to measure the strength of association, but there are conditions for both these measurements to be considered as being equivalent; the most important is that the disease of interest must have a low prevalence in the exposed group. ${ }^{3}$ When this condition is met, RR and OR are a good approach and can be indistinctively used. In the commented report, incidence of the outcomes was very high: $65.3 \%$ (32/49) developed late-onset sepsis and $24.5 \%$ (12/49), necrotizing enterocolitis. Due to the elevated frequency in exposed children, RR and OR shouldn't have been used indistinctively.

Corrected RR for late-onset sepsis and necrotizing enterocolitis shows a strong correlation between antibiotic-exposure time and the development of unfavorable outcomes (late-onset sepsis and necrotizing enterocolitis).

The above observations are by no means intended to invalidate the results reported in the study.

\section{References}

1. Briones-Lara E, Treviño-Báez J, Caballero-Trejo A, Irruegas-Maeda A, Palacios-Saucedo GC, Ramírez-Rosalino MC. Exposición prolongada a antibióticos y riesgo de sepsis tardía (ST) en neonatos de 1,000 a $<$ 1,500 g: estudio de cohorte. Gac Med Mex 2015;151:306-312.

2. Epi-info for Window V7.2. Disponible en: https://www.cdc.gov/epiinfo/ support/downloads.html.

3. Gordis L. Epidemiología. España: Elsevier-Saunders; 2005.
Gac Med Mex. 2018;154:293-293

Contents available at PubMed www.gacetamedicademexico.com 